\title{
Um estudo sobre as intervenções docentes em contextos de atividades investigativas no âmbito de aulas de Matemática do Ensino Superior
}

\begin{abstract}
A study on the teacher interventions in contexts of investigative activities within the Mathematics classes of Higher Education
\end{abstract}

\author{
Karina Alessandra Pessoa da Silva ${ }^{1}$ \\ https:// orcid.org/0000-0002-1766-137X \\ Rodolfo Eduardo Vertuan ${ }^{2}$ \\ https://orcid.org/0000-0002-0695-3086
}

\begin{abstract}
Resumo: Neste artigo apresenta-se resultados de pesquisa que busca discutir a mobilização de conhecimentos dos alunos e o encaminhamento de resolução de atividades investigativas em aulas de Matemática mediadas por intervenções docentes. A fundamentação baseia-se no aporte teórico de atividades investigativas, considerando-as essencialmente abertas e pouco estruturadas, passíveis de abarcar temas e / ou situações de interesse dos alunos e possibilitar a mobilização de conhecimentos de diferentes naturezas. Foram analisadas três atividades desenvolvidas por grupos de alunos de três turmas de um curso de Licenciatura em Química na disciplina de Cálculo Diferencial e Integral I de uma universidade pública. Por meio de análise qualitativa de cunho interpretativo de falas transcritas de episódios-orientação e episódios-apresentação, evidencia-se que as intervenções docentes, em certa medida, cooperam com o desenvolvimento da atividade, possibilitam compartilhamento de conhecimentos entre docente e alunos, estabelecem relações entre áreas interdependentes e, em alguns momentos, direcionam o encaminhamento da atividade.
\end{abstract}

Palavras-chave: Educação matemática. Atividade investigativa. Mobilização do conhecimento. Intervenções docentes. Ensino superior.

\begin{abstract}
This paper presents the results of a research that discusses the students' knowledge mobilization and the referral of the resolution of investigative activities in Mathematics classes mediated by teaching interventions. The position is based on the theoretical contribution of investigative activities, considering them to be essentially open and unstructured, which can cover topics and / or situations of interest to the students and that enable the knowledge mobilization of different natures. Three activities developed by groups of students from three classes of a degree in Chemistry in the discipline of Differential and Integral Calculus I of a public university were analyzed. Through a qualitative interpretative analysis of transcribed statements of episodes-orientation and episodes-presentation, it become evident that the teaching interventions, to a certain extent, cooperate with the evolution of the activity, enabling the sharing of knowledge between teacher and students, and establish relationships between interdependent areas and, at times, direct the activity.
\end{abstract}

Keywords: Mathematics education. Investigative activity. Knowledge mobilization. Teachers' interventions. Higher education.

\footnotetext{
${ }^{1}$ Universidade Tecnológica Federal do Paraná (UTFPR), Departamento Acadêmico de Matemática, Londrina, PR, Brasil. E-mail: <karinasilva@utfpr.edu.br>.

${ }^{2}$ UTFPR, Toledo, PR, Brasil.
} 


\section{Introdução}

Uma prática comum de um dos professores (autores) deste artigo, ao lecionar nos anos iniciais do Ensino Fundamental, consiste em disponibilizar o Material Dourado ${ }^{3}$ para os alunos e requerer que realizem atividades relacionadas às características do sistema de numeração decimal e às operações aritméticas. Neste contexto, principalmente no primeiro ano do Ensino Fundamental, uma das frases mais ditas pelo docente aos alunos é a de que uma dezena equivale a 10 unidades, ou ainda, que uma "barrinha" equivale a "10 cubinhos" no material.

É neste cenário que se dá a primeira experiência consciente do docente no que diz respeito ao alcance e à função do professor nos processos de mobilização do conhecimento ${ }^{4}$ pelos alunos. O fato ocorreu há alguns anos quando, depois de quase seis meses repetindo a mesma frase e solicitando que os alunos verificassem sua validade usando o material, um aluno chama o docente até sua mesa para lhe contar, estupefato, a "descoberta" que acabara de fazer, a de que "uma barrinha (dezena) equivalia a 10 cubinhos (unidades)".

Apesar do descontentamento inicial do docente, que imaginava que o fato de ter pronunciado aquela informação por diversas vezes tinha sido suficiente para que os alunos a tivessem aprendido (e claro, do contentamento porque seu aluno havia mobilizado esse conhecimento), aquele momento constituiu-se também uma oportunidade de o docente refletir sobre os processos de ensino e de aprendizagem. Essa reflexão desencadeou, dentre outros aspectos, a ideia que, embora a aprendizagem seja um processo que aconteça nas relações que o indivíduo estabelece na interação com conhecimentos já aprendidos e na interação com outras pessoas, é um processo que depende essencialmente da pessoa que aprende e, nessa perspectiva, pouco sentido faz os professores centrarem suas aulas nas suas falas, quando deveriam centrá-las nas ações (cognitivas) de seus alunos.

Tomamos as ações cognitivas no sentido atribuído por Flavell (1979), para o qual as ações cognitivas podem ser entendidas como as atividades ou os procedimentos que realizam uma pessoa com vistas a realizar um objetivo cognitivo, tal como o entendimento de uma situação, a interpretação de fatos e informações, o agrupamento de ideias para pensar sobre uma situação, bem como o automonitoramento utilizado na resolução de um problema. Desse modo, parece razoável considerar que no contexto das pesquisas que incidem sobre a dinâmica de uma sala de aula, as intervenções dos professores no que diz respeito à mobilização do conhecimento dos alunos seja um tema que pode contribuir no tocante à compreensão dos mecanismos subjacentes à aprendizagem e à função do docente em um ambiente investigativo. Nesse sentido, entendemos que as intervenções do professor (intervenções docentes) podem ressignificar conhecimentos, estratégias, encaminhamentos, implicando na aprendizagem (PAZUCH; NEHRING, 2012).

Pesquisas que abordam o ambiente investigativo, mais especificamente as atividades investigativas têm sido recorrentes nas diferentes áreas do conhecimento (BASSOLI, 2014; SILVA; TRIVELATO, 2017; VERTUAN; SILVA; BORSSOI, 2017; ZÔMPERO; LABURÚ,

\footnotetext{
${ }^{3}$ Material Manipulável feito de madeira e utilizado para o trabalho com aritmética.

${ }^{4}$ Tomamos conhecimento como tudo o que adquirimos na interação com nosso entorno sociocultural, como resultado da experiência e da reflexão sobre ela, ou seja, como resultado dos processos de aprendizagem.
} 
2011; ZOMPERO; GONÇALVES; LABURÚ, 2017). É nesse contexto que a presente pesquisa se insere no âmbito de atividades investigativas desenvolvidas por uma docente do Ensino Superior, autora desse artigo, ao lecionar disciplinas de Matemática na perspectiva da Educação Matemática.

A coleta de informações se deu em uma universidade pública federal do norte do Estado do Paraná, na disciplina de Cálculo Diferencial e Integral I do curso de Licenciatura em Química, nos anos de 2015 e 2016.

A partir dos dados e da fundamentação teórica pertinente, neste artigo investigamos: Como as intervenções docentes influenciam a mobilização do conbecimento e os encaminhamentos de resolução dos alunos em atividades investigativas de Matemática? Mobilizar consiste em pôr em movimento, preparar para o serviço ou a ação. Neste sentido, entendemos a mobilização do conhecimento na perspectiva de colocar o conhecimento em ação, tornando-o útil (NAIDORF, 2014). Segundo Silva e Trivelato (2017, p. 140), "a ciência que é ensinada na escola precisa contribuir para que os indivíduos possam, em sua vida cotidiana, articular conhecimentos para a tomada de decisões".

Para isso, apresentamos uma discussão dos resultados e inferências realizadas acerca da questão de pesquisa, tomando como ponto de partida os principais aspectos teóricos de atividades investigativas e de mobilização do conhecimento, apresentados na segunda seção deste artigo. $\mathrm{Na}$ terceira seção discutimos os elementos metodológicos considerados na pesquisa. Na quarta seção apresentamos uma descrição de episódios considerados significativos para os interesses desta pesquisa, bem como realizamos uma análise dos mesmos à luz da fundamentação teórica. Finalmente, na quinta seção tecemos nossas considerações finais, que por sua vez, são seguidas das referências bibliográficas.

\section{Educação Matemática e Atividades Investigativas}

No Ensino Superior tem sido recorrente professores das áreas específicas dos cursos (engenheiros, químicos e outros) relatarem dificuldades de seus alunos no enfrentamento de problemas específicos da profissão, da área de formação, mesmo quando estão prestes a se formar e mesmo quando tratam de situações em que são requeridos apenas conhecimentos adquiridos no decorrer do curso.

Se por um lado os docentes que lecionam matemática nesses cursos, por exemplo, muitas vezes desconhecem aplicações do que ensinam nas áreas específicas, por outro, o modo como apresentam os conceitos e organizam suas aulas pode influenciar uma aprendizagem estanque e descontextualizada, bem como contribuir para com a dificuldade desses futuros profissionais na resolução de problemas similares aos que poderão encontrar no exercício da profissão.

E é por considerar de extrema importância o modo como os docentes apresentam os conceitos e organizam suas aulas, que nesse trabalho buscamos discutir as "atividades investigativas" como uma estratégia para a mobilização e uso do conhecimento em aulas de matemática ministradas no Ensino Superior. Essa estratégia possibilita discutir, nas aulas, problemas relacionados às futuras profissões, de forma a tornar "o conhecimento mais útil, proativo e aplicado, porque a utilidade, a proatividade e aplicação são fatores limitantes em algumas áreas do conhecimento" (NAIDORF, 2014, p. 16, tradução nossa), como a Matemática. Segundo, a autora, a "mobilização do conhecimento, nesta perspectiva, é uma forma de tornar o conhecimento útil, aumentando seu valor em relação à sua utilidade" (NAIDORF, 2014, p. 14, tradução nossa). 
Entendemos que atividades investigativas são essencialmente abertas e pouco estruturadas, que podem abarcar temas/situações de interesse dos alunos. Estes, por sua vez, ao explorar tais situações, criam suas próprias questões, elaboram hipóteses, planejam e executam ações, validam (ou não) tanto essas ações quanto as respostas encontradas para as questões, bem como comunicam e justificam os resultados da investigação para os demais alunos da turma, quiçá para outros interessados externos à comunidade universitária.

Para Fiorentini e Lorenzato (2006, p. 29) as atividades investigativas são “abertas, exploratórias e não diretivas do pensamento do aluno e [...] apresentam múltiplas possibilidades de alternativa de tratamento e significação". Desse modo, aventurar-se em atividades investigativas e buscar soluções para questões muitas vezes suscitadas por contextos inicialmente não matemáticos implica em valer-se de conhecimentos já consolidados ou em vias de consolidação, traçar objetivos e planejar ações com vistas a atingi-los, realizar pesquisas quando os conhecimentos não forem suficientes para superar obstáculos, enfim, envolver-se efetivamente com o problema e a busca por uma solução. Neste sentido, Ponte, Brocardo e Oliveira (2003, p. 23) destacam que

O envolvimento ativo do aluno é condição fundamental da aprendizagem. $\mathrm{O}$ aluno aprende quando mobiliza os seus recursos cognitivos e afetivos com vistas a atingir um objetivo. Esse é, precisamente, um dos aspectos fortes das investigações. Ao requerer a participação do aluno na formulação de questões a estudar, essa atividade tende a favorecer o seu envolvimento na aprendizagem.

Em se tratando de uma aula com atividades investigativas, "o primeiro grande passo [...] é identificar claramente o problema a resolver" (PONTE; BROCARDO; OLIVEIRA, 2003, p. 16). E é na busca por uma solução para esse problema - ou ainda, para uma ou várias questões elaboradas a partir desse problema - que se desenvolvem processos matemáticos como procurar regularidades, formular, testar, generalizar, relacionar representações, conceituar, ressignificar conceitos e construir novos. Processos estes que, embora sejam influenciados pela intervenção do docente que procura mediar as ações e discussões, são de responsabilidade dos alunos, os quais devem "sentir que as suas ideias são valorizadas e que se espera que as discuta com os colegas, não sendo necessária a validação constante por parte do professor" (PONTE; BROCARDO; OLIVEIRA, 2003, p. 28).

Entendemos que é no esforço dos alunos ao desenvolverem atividades investigativas que reside a possibilidade de os mesmos mobilizarem conhecimentos. Essa mobilização, por sua vez, dá movimento e dinamicidade às compreensões que os alunos constroem acerca dos conceitos, os quais são, nesta perspectiva, provisórios e sujeitos aos novos contextos de investigação em que, porventura, forem utilizados.

Estes contextos de investigação, por sua vez, podem suscitar a mobilização de conhecimentos de "naturezas e finalidades distintas", que "se desenvolvam de modo imbrincado e interdependente" (VERTUAN; SILVA; BORSSOI, 2017, p. 13). Vertuan, Silva e Borssoi (2017, p. 13), ao realizarem pesquisa a partir de atividades investigativas segundo perspectiva da Modelagem Matemática, reconhecem que, ao desenvolver as atividades, diferentes conhecimentos foram mobilizados, desde "aqueles relacionados ao uso de estratégias e algoritmos, aqui denominados de procedimentais, aqueles que dizem dos conceitos matemáticos e de outras áreas do 
saber, ou conceituais", até aqueles "relacionados à comunicação de ideias e ao entendimento de outras perspectivas".

No que tange a este último, quando comunicam e justificam suas ideias uns aos outros, ou mesmo o fazem para o docente, os alunos precisam se posicionar e argumentar a favor de uma opinião. No entanto, "posicionar-se significa levantar ideias e pontos de vistas não como verdades absolutas, mas como algo que pode ser examinado" (ALRØ; SKOVSMOSE, 2010, p. 70). Ao se posicionar e ao estar disposto a entender a perspectiva, ideia e opinião do outro, o que se verifica é a possibilidade de construir uma perspectiva de encaminhamento comum, coletiva, que não existiria se não fosse o trabalho conjunto.

Muito embora nas atividades investigativas o processo de resolução seja centrado nos alunos, o modo como os professores intervêm e medeiam as discussões precisa favorecer o envolvimento dos alunos e a autonomia dos mesmos. Silva e Villani (2009, p. 30), afirmam que "o professor se torna um membro do grupo, assumindo algum papel que lhe é transferido na relação com os alunos”. Para isso, as intervenções docentes precisam considerar as perspectivas dos alunos.

Após estabelecer uma atenção mútua, o professor pode perceber a perspectiva do aluno, examinando, por exemplo, como ele entende certo problema. Naturalmente, várias perspectivas possíveis e diferentes formas de abordagem de uma tarefa ou problema podem ser percebidas. Talvez seja difícil para o aluno expressar sua ideia matematicamente, ou, em geral, expressar a perspectiva que ele quer estabelecer para o problema. O professor pode atuar como um facilitador ao fazer perguntas com uma postura investigativa, tentando conhecer a forma com que o aluno interpreta o problema (ALR $\varnothing$; SKOVSMOSE, 2010, p. 70).

Há de se reconhecer, no entanto, que realizar intervenções também não é tarefa simples, embora, inferimos que o modo como se dá essa intervenção influencia em certa medida os encaminhamentos de resolução tomados pelos alunos, bem como as possibilidades de discussão e mobilização do conhecimento. Neste contexto é que se dá essa pesquisa, cujo objetivo é investigar como as intervenções docentes influenciam a mobilização do conhecimento e os encaminhamentos de resolução dos alunos em atividades investigativas de Matemática no Ensino Superior.

\section{Aspectos metodológicos}

Para empreender a investigação, orientamos nossas análises em atividades desenvolvidas por alunos do curso de Licenciatura em Química de uma universidade pública localizada no estado do Paraná. As atividades foram propostas e desenvolvidas na disciplina de Cálculo Diferencial e Integral I, que é ofertada no primeiro período letivo do curso (regime semestral). Tal disciplina tem carga horária de 108 horas/aula.

Para além dessa carga horária, os alunos do curso de Licenciatura em Química precisam cumprir 6 horas/aula em atividade extraclasse que é designada por Atividade Prática Supervi- 
sionada (APS). Essa atividade, orientada pelo professor, tem como objetivo estabelecer relações teórico-práticas na disciplina, permitindo desenvolver competências provenientes de estudos dirigidos, trabalhos individuais, trabalhos em grupo, desenvolvimento de projetos, atividades em laboratório, atividades de campo, oficinas, pesquisas, estudos de casos, seminários, desenvolvimento de trabalhos acadêmicos, práticas de ensino e atividades específicas dos cursos de licenciatura, dentre outras.

Para a realização da APS, a professora de Cálculo Diferencial e Integral I, autora deste artigo, propõe aos alunos o desenvolvimento de atividades investigativas em que, em grupos, devem escolher uma temática, de preferência, relacionada ao curso (consequentemente, à futura profissão) e investigar matematicamente. A professora, quando requerida, orienta o desenvolvimento das atividades em horário extraclasse. Nas últimas aulas do semestre, os alunos organizam uma apresentação dos trabalhos desenvolvidos.

Nossa pesquisa foi realizada durante os anos de 2015 e 2016. Com isso, três turmas foram investigadas em três semestres letivos e, ao todo, foram desenvolvidas 28 atividades investigativas por 28 grupos de alunos.

As orientações com a professora, bem como a apresentação dos trabalhos, foram gravadas e/ou filmadas, constituindo dois tipos de episódios que denominamos episódio-orientação e episódio-apresentação. Para isso, todos os envolvidos assinaram um termo de consentimento livre e esclarecido. As gravações foram transcritas e, após sua leitura, selecionamos as atividades e os episódios para nossa análise. Considerando os alcances e os propósitos desta investigação, tratamos apenas de três atividades desenvolvidas por três dos grupos supracitados.

A escolha de três atividades para análise, bem como dos episódios a elas relacionados, se deu em virtude de que nessas atividades e episódios, professora e alunos conversam sobre a atividade, de modo que as falas da docente parecem ser caracterizadas como "intervenções", principalmente devido às suas possíveis influências no desencadeamento de ações dos alunos frente à atividade. Além disso, procuramos escolher uma atividade por turma (Quadro 1).

Quadro 1: Atividades analisadas

\begin{tabular}{|c|c|c|c|}
\hline Turma & T1: 2015/01 & T2: 2015/02 & T3: 2016/01 \\
\hline Temática & Etanol na gasolina & Temperatura da água na garrafa & Ebulioscopia $^{5}$ \\
\hline
\end{tabular}

Fonte: elaborado pelo autores.

As informações que utilizamos para a análise consistem nas falas e gestos dos alunos durante orientações e apresentações. Para nos referirmos aos alunos utilizamos a letra A, o número que o diferencia dos colegas do grupo e o número da turma. Por exemplo, A1T1 refere-se ao aluno 1 da turma 1, A2T2 refere-se ao aluno 2 da turma 2 e, assim, sucessivamente. A

\footnotetext{
${ }^{5}$ Ebulioscopia é uma propriedade coligativa que estuda a variação de temperatura de ebulição de acordo com a quantidade de soluto não volátil (que não evapora) presente em uma solução. 
descrição "Aluno da turma" estará presente quando um aluno não pertencente ao grupo tiver alguma participação. Utilizamos a letra P para a professora. Há episódios analisados dos quais fizemos recortes das falas, visto que os alunos abordavam assuntos não relacionados à atividade. Para isso, utilizamos o recurso supressão ([...]). Em alguns momentos, utilizamos os colchetes para interpolações de ações dos alunos que davam continuidade à atividade.

A metodologia de pesquisa que adotamos fundamenta-se na abordagem qualitativa, que segundo Garnica (2004, p. 86), tem como características:

(a) a transitoriedade de seus resultados; (b) a impossibilidade de uma análise a priori, cujo objetivo da pesquisa será comprovar ou refutar; (c) a não neutralidade do pesquisador que, no processo interpretativo, vale-se de suas perspectivas e filtros vivenciais prévios dos quais não consegue se desvencilhar; (d) que a constituição de suas compreensões dá-se não como resultado, mas numa trajetória em que essas mesmas compreensões e também os meios de obtê-las podem ser (re)configuradas; e (e) a impossibilidade de se estabelecer regulamentações, em procedimentos sistemáticos, prévios, estáticos e generalistas.

Vale destacar que as APS constituíram $20 \%$ da nota final da disciplina e que foram desenvolvidas ao longo de cada semestre.

A análise dos episódios leva em consideração o referencial teórico estabelecido com relação às atividades investigativas e à mobilização do conhecimento. Essa articulação com o referencial teórico possibilita uma maior compreensão do fenômeno em estudo.

\section{Mobilização do conhecimento em atividades investigativas: episódios analisados}

Nesta seção analisamos os episódios considerados significativos que nos possibilitaram inferir sobre como as intervenções docentes influenciaram a mobilização do conhecimento e os encaminhamentos de resolução dos alunos em atividades investigativas de matemática.

No estudo da quantidade de etanol presente em amostras de gasolina coletadas em diferentes postos de combustível da cidade, o grupo formado por quatro alunos da T1 procurou a professora para expor a ideia de atividade investigativa que estava interessado em realizar, conforme excerto do episódio-orientação em que trata do tema de interesse e que foi transcrito:

A1T1: Professora a gente quer estudar a quantidade de etanol que existe na gasolina, vimos que é permitida uma certa quantidade. Será que os postos de Londrina estão dentro da lei?

P: Como vocês pensaram a situação?

A2T1: Coletar gasolina em postos e usar um procedimento que mede a quantidade de etanol presente na coleta. Daí a gente vê a porcentagem e se ela está de acordo com o regulamentado.

P: De quanto é essa quantidade regulamentada? 
A3T1: A gente leu em uns documentos da Agência Nacional de Petróleo e viu que é permitido no máximo vinte e cinco por cento de etanol na gasolina. Daí a gente poderia analisar a concentração, em porcentagem, de etanol na gasolina comercializada na cidade de Londrina. Pode ser?

P: Penso que sim. E se o grupo se interessa pelo tema! Onde vocês desenvolverão os procedimentos para analisar a quantidade de etanol?

A2T1: No laboratório, é bem simples.

P: Cuidado, ficar mexendo com gasolina... Usem os equipamentos certinbo!

A1T1: A gente sabe professora, estudamos isso direto em Quimica Geral.

Com as intervenções da professora, os alunos tiveram que explicitar os procedimentos que utilizariam para a análise das amostras de gasolina. No entanto, os alunos já haviam pesquisado e apresentaram conhecimentos fundamentados em documentos nacionais sobre a quantidade de etanol permitida. A professora também chama a atenção para os cuidados em manipular materiais no laboratório, por desconhecer esses procedimentos que, para os alunos, é corriqueiro nas aulas da disciplina de Química Geral.

No episódio-orientação, a professora busca entender qual problema os alunos pretendem investigar a partir de um tema de interesse. Com os questionamentos, a professora tem a intenção de "reformular as perspectivas para ter certeza que entendeu o que os alunos dizem" (ALRØ; SKOVSMOSE, 2010, p. 71), encaminhamento presente em uma atividade investigativa.

No entanto, é no episódio-apresentação que parece haver uma mobilização de conhecimentos químicos, conforme excerto transcrito:

\section{$[\cdots]$}

A3T1: Para mostrar o que fizemos, vamos mostrar aqui na prática. Vamos fazer e vocês só observam. [explica os procedimentos] O que vocês acham que vai acontecer? [silêncio]

Aluno da turma: A gasolina vai se separar da água.

A1T1: Muito bem. E o etanol?

Aluno da turma: Ele não se separa né?

[todos observam a separação da gasolina da água destilada]

P: Só dá certo com água destilada?

A2T1: Não professora, com água da torneira também, mas a gente seguiu os procedimentos indicados para não interferir nos resultados.

P: Por que isso acontece?

A4T1: A gasolina é apolar, porque a diferença de eletronegatividade entre o $\mathrm{C} e \mathrm{H}$ é muito baixa, já a água contém o $O$, então é polar.

A1T1: Sim, o etanol também é polar. O que mantém o etanol e a gasolina juntos é a parte apolar do etanol, com isso esta gasolina tem um pouco de etanol. Com isso, quando colocamos água na gasolina a parte polar do etanol interage com a água, logo a água separa o etanol da gasolina.

P: Então a água destilada se mistura com o etanol da gasolina e o separa dela?

A2T1: Sim. Fizemos isso com outras duas amostras. Coletamos em três postos de Londrina. E agora é a parte da matemática [risos, apresentam a abordagem matemática]. 
No início da apresentação, A3T1 encaminha a atividade realizando questionamentos para a turma, demonstrando um conhecimento com procedimentos didáticos que possibilitam a participação dos colegas. Em seguida, A1T1 valida uma resposta do colega e sugere outro questionamento para encaminhar a apresentação. Esse fato pode estar relacionado à mobilização de conhecimentos didáticos estudados em outras disciplinas do curso de licenciatura em que estão inseridos.

Quando a professora realiza a intervenção questionando "Por que isso acontece?", permite uma mobilização nos conhecimentos químicos de A4T1 e A1T1, que os explicitam discorrendo sobre conceitos de eletronegatividade e polaridade, respectivamente. Já A2T1 aproveita o questionamento da professora sobre a mistura de gasolina e água destilada para apresentar a abordagem matemática que realizaram para o estudo da situação. Isso corrobora com as afirmações de Silva e Villani (2009, p. 31) sobre o fato de que quando "o professor estiver presente entre os alunos, será necessário que esteja atento também para as mensagens que ele recebe dos alunos", procurando estabelecer a comunicação.

Os comentários dos alunos permitem-nos inferir que conhecimentos de distintas áreas foram mobilizados de modo que "[...] se desenvolvam de modo imbrincado e interdependente" (VERTUAN; SILVA; BORSSOI, 2017, p. 13), atribuindo um caráter interdisciplinar para a atividade investigativa que estavam desenvolvendo. Com isso, a atividade parece mobilizar não apenas o que um aluno sabe, mas como esse aluno usa o que sabe (SCHOENFELD, 1987).

Para estudar o aquecimento da água de uma garrafa de $500 \mathrm{ml}$, lacrada, que se encontrava no interior de um veículo fechado exposto ao Sol, o grupo de três integrantes da T2, com um termômetro infravermelho, mediu a temperatura em diferentes intervalos de tempo, em uma manhã do mês de outubro de 2015 cuja temperatura ambiente foi de aproximadamente $30^{\circ} \mathrm{C}$. Em orientação com a professora especificaram suas intenções de estudo, conforme episódio-orientação transcrito a seguir:

A1T2: Professora, nós coletamos os dados com o termômetro infravermelho da empresa que eu trabalho, mas não sabemos o que vamos fazer.

P: Que informações vocês têm?

A2T2: A temperatura da água da garrafa no painel do carro.

P: Com essas informações o que vocês gostariam ou poderiam estudar?

A1T2: Como assim o que a gente gostaria?

P: Bom, vocês têm os dados aí, deixa eu ver? [manuseando as informações escritas]. Como vocês fizeram?

A1T2: Olha aqui na foto professora [abrindo o arquivo no computador]. Esse termômetro [apontando para foto] eu uso lá na firma para ver a temperatura de algumas peças de dentro do motor dos carros. Dai a gente usou para ver a temperatura da água da garrafa que muitas vežes a gente deixa no carro. De uma em uma hora, a A2T2 ia anotando os valores que eu fiz a leitura, sem abrir o carro. Fica mais real né? P: Certo, e o que, ou melhor que problema vocês podem estudar?

A1T2: Ah, não sei!

P: Que pergunta vocês poderiam responder com esses dados?

A2T2: A gente escreve uma pergunta para o que temos?

P: Isso. O que vocês podem responder, ou o que gostariam de saber em relação à temperatura da água no interior do carro? É uma situação que ocorre constantemente. 
A1T2: Por isso que a gente quis estudar!

A3T2: E se a gente firesse o gráfico?

A1T2: Ela falou uma pergunta!

A1T2: É. Aí não sei, acho bom conversarmos aqui.

[alunos conversam sobre a situação e sobre coleta de dados].

P: E o que decidiram?

A3T2: E se a gente determinasse o tempo em que a água chegasse à temperatura ambiente?

P: E qual era a temperatura ambiente no momento da coleta?

A1T2: A gente não anotou, mas dá para procurar a temperatura média prevista para o dia nesses sites. Vamos A3T2, acessa a internet aí! [...]

No desenvolvimento da atividade investigativa, os alunos primeiramente coletam os dados, sem se atentarem a um problema a ser estudado. O interesse inicial pelo tema, escolhido pelo grupo, pode ter sido suficiente para o engajamento com a atividade e a discussão de conceitos matemáticos e extra matemáticos ligados a ela. Com isso, o interesse do grupo se configura em realizar uma tarefa burocrática de matematizar uma situação - tarefa da disciplina.

As intervenções da professora na orientação criam uma instabilidade no grupo de modo que os alunos agem procurando entender a intenção da professora com a tarefa. Para a professora é evidente a necessidade de um problema a ser investigado na atividade proposta, já os alunos apresentam dificuldade em escrever um problema que pudessem associar à matemática. $\mathrm{O}$ que há, nessa situação, é um problema de comunicação no que tange ao entendimento da tarefa. A professora solicita que os alunos esclareçam qual é o problema que pretendem estudar e os alunos intentam matematizar a situação, fazendo uma representação gráfica. A intervenção da professora acaba por indicar um encaminhamento para a atividade em que os alunos necessitam buscar outras informações para definir um problema que pudessem estudar a partir dos dados. Essa intervenção coopera com os alunos, no sentido de que eles percebam perspectivas para desenvolver a atividade. A partir de "questões hipotéticas, os alunos prosseguem com questões ampliadoras, esclarecedoras” (ALRØ; SKOVSMOSE, 2010, p. 108). Nesse sentido, a mobilização do conhecimento em articular dados a um problema (em língua natural) que pudesse ser resolvido por vias matemáticas proporciona o engajamento dos alunos.

Ainda, durante a orientação, os alunos apresentaram encaminhamentos matemáticos para investigar a situação, conforme excerto do episódio transcrito:

$[\ldots]$

A3T2: Olha professora, o Curve nos apresentou várias curvas e essa não era a primeira!

A2T2: Mas era a melhor para a situação!

P: E a representa?

A1T2: Sim, para os dados que a gente tem e para responder o problema acho que dá certo sim, a gente validou no Excel e achou boa! Agora...

A3T2: E se achar ou melhor calcular o limite. [começa realizar os cálculos]

A1T2: Ab é, dá para encontrar a... como é o nome?

P: Assintota?

A1T2: Isso. 
Ao realizar uma intervenção nas explicações de A2T2, a professora "exige" que os alunos retomem a situação de maneira que evidenciem se a matemática utilizada representa a situação estudada. Isso se deve ao fato de que as atividades investigativas "apresentam múltiplas possibilidades de alternativa de tratamento e significação" (FIORENTINI; LORENZATO, 2006, p. 29), especialmente no contexto matemático. No entanto, há de se estabelecer inter-relações com a situação investigada.

Nesse episódio, no entanto, a professora intervém de modo mais diretivo, com orientações mais específicas sobre o que deveriam fazer os alunos. Isso porque em uma atividade investigativa, há "a possibilidade de que os participantes no processo não serem capazes de captar uma perspectiva em certa sugestão, sendo necessário que uma 'autoridade' destaque certas ideias que mereçam atenção" (ALRØ; SKOVSMOSE, 2010, p. 109).

$\mathrm{Na}$ apresentação dos resultados para a sala de aula, além da abordagem matemática para a situação, os alunos tecem outras considerações, conforme excerto do episódio-apresentação transcrito:

\author{
$[\ldots]$ \\ A1T2: Professora, nunca beba água que ficou dentro do carro! \\ P: Por quê? \\ A2T2: Os meninos encontraram uma reportagem aqui que afirma que o plástico da \\ garrafa, quando aquecido, libera uns produtos químicos que podem causar câncer! \\ P: Que coisa! Igual quando aquecemos plástico no forno de micro-ondas? \\ A1T2: Aham! Temos que ter cuidado! \\ A3T2: Aqui na reportagem diz que pesquisadores da Universidade da Flórida testaram \\ água de garrafa que ficou à temperatura de $70^{\circ} \mathrm{C}$ e havia aumentado a concentração \\ de bisfenol e antimônio por causa do plástico da garrafa! \\ A1T2: E o antimônio é cancerígeno."
}

Por meio do desenvolvimento da atividade investigativa, os alunos necessitaram mobilizar conhecimentos de diferentes naturezas, atrelados aos conhecimentos matemáticos e aos conhecimentos químicos. Esse é um dos objetivos pelos quais propomos atividades investigativas em sala de aula do Ensino Superior, para engajar os alunos em discussões relacionadas às suas futuras profissões, via um viés matemático, tornando "o conhecimento mais útil, proativo e aplicado" (NAIDORF, 2014, p. 16, tradução nossa). Além disso, o professor se aventura a lidar com uma área que possivelmente não tenha conhecimento, aprendendo com seus alunos.

$\mathrm{Na}$ turma T3, três alunos escolheram estudar um fenômeno químico chamado ebulioscopia. Para isso, os alunos aqueceram misturas com diferentes quantidades de solutos. A coleta de dados foi realizada no Laboratório de Química da universidade sob a supervisão de uma aluna de iniciação científica e de um técnico. Com um termômetro digital tipo espeto, os alunos mediram a temperatura de ebulição das diferentes misturas. Com os dados coletados, os alunos buscaram orientações da professora, com o intuito de entender o que poderiam desenvolver matematicamente conforme transcrição do episódio-orientação:

A1T3: Professora, a gente estudou a ebulioscopia.

P: Ebulioscopia? 
A2T3: É, o estudo da temperatura de ebulição de uma solução de acordo com a quantidade de um soluto.

A1T3: Soluto não volátil.

A2T3: É, soluto não volátil, como o cloreto de sódio que é sal de cozinha que nós utilizamos. Nós sabemos que quanto mais soluto bá na solução maior é a temperatura de ebulição. E vimos isso no experimento. Mas e agora a pergunta, a gente não sabe! P: Deixa eu ver. E essa temperatura da água sem sal aqui, deveria ser cem graus Celsius, não é? [apontando para a tabela no computador de A1T3].

A1T3: É... a gente queria ver se pode desconsiderar isso aqui no nosso estudo.

P: Mas o que vocês querem estudar?

A1T3: Um modelo matemático, pode ser?

P: Para que?

A3T3: E se a gente pensasse em fazer uma função que dependendo da quantidade de soluto, obtemos a temperatura?

A2T3: Mas chega um momento que a solução fica saturada.

A1T3: Desconsideramos isso nas hipóteses. Pode ser professora? Porque nos livros que a gente estudou, têm algumas tabelas e gráficos, mas a função com y e x não aparece.

P: E o que são x e y?

A2T3: As variáveis que são o soluto e a temperatura. Escreve ai nosso problema A3T3. E professora vamos usar o Excel e aquele programa... o... como é o nome?

A1T3: Curve.

A2T3: Isso, curve.

P: Qual o problema?

A2T3: Aquele que A3T3 falou!

P: A3T3 você pode repetir ou anotar?

A3T3: Escrevi aqui professora! [...]

No episódio-orientação da atividade podemos evidenciar que a mobilização de conhecimento não se dá de mão única, do professor para o aluno. Nesse caso, o que se percebe é que a professora desconhece os assuntos da área de formação pelos quais os alunos se interessam e, por isso, faz questionamentos para tentar compreender do que estão falando, já que são eles que dominam os aspectos não matemáticos da situação. Mesmo assim, se insere no debate, e busca realizar intervenções que permitam aos alunos desenvolverem alguma matemática a partir do campo que dominam, a química. Para Silva e Villani (2009, p. 44),

[...] conhecer o processo de aprendizagem dos alunos nos grupos constitui uma informação importante para o professor poder regular as atividades de sala de aula e modificar suas intervenções. Isso implica dizer que, quando o professor opta por uma dinâmica que envolve grupos, o conhecimento do seu processo de desenvolvimento é muito importante para que as intervenções alcancem a meta visada.

Professora e alunos mobilizam conhecimentos de forma compartilhada. Isso ocorre porque os "participantes da investigação conduzem suas atividades e são responsáveis pela forma 
como elas se desenrolam e pelo que podem aprender com elas" (ALRØ; SKOVSMOSE, 2010, p. 124). Nesse sentido, Milani (2017, p. 40) afirma que professor e alunos "estão em contato, e o que se deseja é que haja uma relação interpessoal igualitária".

Com as intervenções, a professora cria um ambiente educacional em que os alunos necessitam mobilizar conhecimentos sobre o fenômeno de ebulioscopia para inseri-la no contexto, de modo que ela os auxilie na abordagem matemática. Ao mesmo tempo, a professora intervém com questionamentos de modo que possibilita inferir sobre as interpretações matemáticas para as mesmas. Os alunos reconhecem que em atividades investigativas é possível simplificar a situação para o estudo e propõem desconsiderar o valor da temperatura da água sem o soluto e a saturação da mistura, bem como atribuir significado para as variáveis $x$ e $y$ para a situação.

No episódio-apresentação, para representar a situação que estavam investigando, os alunos solicitam a orientação da professora para poderem validar o encaminhamento. No entanto, a professora intervém realizando questionamentos que se referem a interpretações matemáticas e também sugere que os alunos decidam entre si sobre a continuidade do desenvolvimento da atividade, conforme excerto:

$[\cdots]$

A2T3: Quando a gente tá lá na aula de química, no laboratório, não pensamos nessas coisas. Mas agora, na aula de cálculo onde vimos função, dominio, imagem, limite, derivadas e outras coisas que ainda veremos, a gente fica pensando como fazer uso disso. Eu pensei em calcular a derivada aqui. E já sabemos que derivada é a taxa de variação... aqui taxa de variação da temperatura de ebulição em função da quantidade de soluto misturado.

P: E essa taxa aí, o que ela representa, já que você a mencionou.

A2T3: É uma função. Bom dá para fazer o gráfico, talvez com algum software e ver o comportamento dessa função. Ai outra coisa se a derivada é positiva, a função original é crescente, se é negativa, é decrescente. Dá para estudar ponto de máximo, minimo e por ai vai. Se a gente tem o gráfico ajuda bastante nisso. Vamos calcular a derivada aqui e usar o GeoGebra para ver. O que acha professora, tá bom isso?

P: Decidam entre vocês.

A2T3: A professora nunca diz que sim nem que não. Que impasse. Mas vamos lá deixando cada vez. mais, como se fala... sofisticado nosso modelo. [risos]

[os alunos realizam cálculos]

A partir de conhecimentos matemáticos explícitos por A2T3, a professora faz intervenções no intuito de que o aluno mobilize seus conhecimentos para interpretar tais conhecimentos com a situação que estava estudando. A fala de A2T3 de que "A professora nunca diz que sim nem que não" denota um estranhamento do aluno em relação ao modo de lidar da professora em um ambiente de aula na perspectiva investigativa, pois pode estar adaptado a aulas em que respostas a questionamentos se limitam em "está certo" ou “está errado". Estando errado, a professora indica como devem proceder e os alunos têm sucesso na finalização da tarefa. No entanto, como afirmam AlrØ e Skovsmose (2010, p. 36), "isso não quer dizer, contudo, que eles estejam aprendendo alguma coisa. Parece mais uma técnica que os alunos desenvolveram para participar das aulas". 


\section{Considerações finais}

Na investigação apresentada neste artigo, procuramos evidenciar como as intervenções docentes influenciam a mobilização do conhecimento e os encaminhamentos de resolução de alunos em atividades investigativas de Matemática, no âmbito da disciplina de Cálculo Diferencial e Integral I de um curso de Licenciatura em Química. Isso se deve ao fato de que entendemos a necessidade de discutir problemas relacionados às futuras profissões via aspectos matemáticos abordados nas aulas de Cálculo Diferencial e Integral I. Essa abordagem vai ao encontro da caracterização de utilidade, proatividade e aplicabilidade do conhecimento proposto por Naidorf (2014).

Considerando que Atividades Práticas Supervisionadas são aquelas que permitem o estabelecimento de relações teórico-práticas na disciplina, desenvolvendo competências diversas relativas às diferentes atividades que podem ser desenvolvidas, reconhecemos que estas se constituíram um espaço em que atividades investigativas essencialmente abertas e pouco estruturadas podem ser propostas para que os alunos discutam e desenvolvam temas/situações de interesse, possibilitando a mobilização de conhecimentos de diferentes naturezas.

Em se tratando de alunos do curso de Licenciatura em Química, a "promoção de atividades investigativas com enfoque experimental possibilita a integração de objetivos conceituais e epistêmicos" (SILVA; TRIVELATO, 2017) nos quais os conhecimentos empíricos evidenciam a natureza dos conhecimentos químicos. Todavia, a articulação com conhecimentos matemáticos é mediada com as orientações e intervenções da professora ao "fazer perguntas com uma postura investigativa, tentando conhecer a forma com que o aluno interpreta o problema” (ALRØ; SKOVSMOSE, 2010, p. 70).

Nos episódios que ilustram este artigo, a intervenção da professora, por vezes, tinha a intenção de conseguir entender, ela mesma, assuntos que, embora para ela fossem desconhecidos, para os alunos eram corriqueiros e, por isso, constituíam conhecimentos já consolidados. Realizar a análise de amostras de gasolina e estudar a ebulioscopia eram procedimentos corriqueiros por parte dos alunos nas disciplinas do curso. Nestes casos, a intervenção docente ("Só dá certo com água destilada?", "Por que isso acontece?", "Ebulioscopia?’), permitiu aos alunos mobilizarem conhecimentos já consolidados e revisitarem aspectos destes conhecimentos na medida em que os explicavam para a docente.

Em outros momentos, a intervenção parecia suscitada pela necessidade que a professora tinha de entender a perspectiva dos alunos para, a partir de então, contribuir para com o encaminhamento de resolução deles. Realizar intervenções do tipo "Como vocês pensaram a situação?" e "Com essas informações o que vocês gostariam ou poderiam estudar?" a fim de entender os encaminhamentos de análise da gasolina, bem como criar uma instabilidade ao solicitar o problema a ser investigado no estudo da temperatura da água no interior do veículo, respectivamente, pareceu pertinente ao congregar perspectivas e direcionar encaminhamentos, quando os alunos não sabiam ao certo quais ações considerar.

Há de se considerar, ainda, que sendo a docente responsável pela disciplina de Cálculo Diferencial e Integral I e tendo como incumbência, por isso, o ensino dos conceitos relativos à disciplina, um tipo de intervenção se mostrou recorrente. Trata-se das intervenções que visavam levar os alunos a mobilizarem os conhecimentos matemáticos e as relações entre os conhecimentos matemáticos e às situações em que emergiram. Ao escolher uma curva, dentre 
aquelas apresentadas por um software, para o estudo da temperatura da água no interior do veículo, a professora intervém com o questionamento - "E a representa?" - fazendo com que os alunos interpretem-na com a situação. No estudo da ebulioscopia, no episódio-apresentação, a intervenção da professora - "E essa taxa aí, o que ela representa, já que você a mencionou" - procurou inferir sobre o conhecimento do aluno sobre a derivada da função para a propriedade coligativa que estava investigando.

De modo geral, a partir do recorte apresentado neste artigo, inferimos, por meio de uma análise qualitativa de cunho interpretativo das falas dos alunos transcritas de episódios-orientação e episódios-apresentação, que as intervenções docentes, em certa medida, influenciam o desenvolvimento e o pensar a atividade, possibilitam compartilhamento de conhecimentos entre docente e alunos, estabelecem relações entre áreas interdependentes e, em alguns momentos, direcionam o encaminhamento da atividade.

É nessa perspectiva que a experiência de um dos docentes nos anos iniciais também exemplifica o alcance e as possibilidades das influências do docente no que tange aos processos de aprendizagem e de mobilização de conhecimentos pelos alunos. Concebendo que esses processos dependem essencialmente da atividade do aluno, um professor com atitude inquisitiva, que trabalha com atividades investigativas, precisa, necessariamente, considerar as perspectivas e ideias de seus alunos, de modo que as intervenções potencializem a construção/mobilização de conhecimentos. Isso implica em aulas com espaços para os estudantes pensarem, debaterem ideias e serem ouvidos. Procedendo assim, centrando as práticas docentes nas ações (cognitivas) dos alunos e não na apresentação de informações via exposição pelos professores, manifestações como a daquele aluno, de que "uma barrinha (dezena) equivalia a 10 cubinhos (unidades)", podem se configurar manifestações constantes no ambiente escolar.

\section{Referências}

ALRØ, H.; SKOVSMOSE, O. Diálogo e aprendizagem em educação matemática. Belo Horizonte: Autêntica, 2010.

BASSOLI, F. Atividades práticas e o ensino-aprendizagem de ciência(s): mitos, tendências e distorções. Ciência \& Educação, Bauru, v. 20, n. 3, p. 579-593, 2014. Disponível em: <http://dx.doi.org/10.1590/1516-73132014000300005>. Acesso em: 17 maio 2018.

FIORENTINI, D.; LORENZATO, S. Investigação em educação matemática: percursos teóricos e metodológicos. Campinas: Autores Associados, 2006.

FLAVELL, J. H. Metacognition and cognitive monitoring: a new area of cognitive developmental inquiry. American Psychologist, Washington, v. 34, n. 10, p. 906-911, 1979. Disponível em: <http://dx.doi.org/10.1037/0003-066X.34.10.906>. Acesso em: 17 maio 2018.

GARNICA, A. V. M. História oral e educação matemática. In: BORBA, M. C.; ARAUJO, J. L. (Org.). Pesquisa qualitativa em educação matemática. Belo Horizonte: Autêntica, 2004. p. 77-98. 
MILANI, R. "Sim, eu ouvi o que eles disseram": o diálogo como movimento de ir até onde o outro está. Bolema, Rio Claro, v. 31, n. 57, p. 35-52, 2017. Disponível em: <http://dx.doi. org/10.1590/1980-4415v31n57a02>. Acesso em: 17 maio 2018.

NAIDORF, J. Knowledge utility: from social relevance to knowledge mobilization.

Education Policy Analysis Archives, Tempe, v. 22, n. 89, p. 1-31, 2014.

PAZUCH, V.; NEHRING, C. M. A vivência de uma intervenção docente: reflexões sobre o ensino e a aprendizagem de matemática. Práxis Educativa, Ponta Grossa, v. 7, n. 2, p. 511-531, 2012.

PONTE, J. P.; BROCARDO, J.; OLIVEIRA, H. Investigações matemáticas na sala de aula. Belo Horizonte: Autêntica, 2003.

SCHOENFELD, A. H. What's all the fuss about metacognition? In: SCHOENFELD, A. H. (Org.). Cognitive science and mathematics education. London: Lawrence, 1987. p.189-215.

SILVA, G. S. F.; VILLANI, A. Grupos de aprendizagem nas aulas de física: as interações entre professor e alunos. Ciência \& Educação, Bauru, v. 15, n. 1, p. 21-46, 2009. Disponível em: <http://dx.doi.org/10.1590/S1516-73132009000100002>. Acesso em: 17 maio 2018.

SILVA, M. B.; TRIVELATO, S. L. F. A mobilização do conhecimento teórico e empírico na produção de explicações e argumentos numa atividade investigativa de biologia.

Investigações em Ensino de Ciências, Porto Alegre, v. 22, n. 2, p. 139-153, 2017.

Disponível em: <http://dx.doi.org/10.22600/1518-8795.ienci2017v22n2p139>. Acesso em: 17 maio 2018.

VERTUAN, R. E.; SILVA, K. A. P.; BORSSOI, A. H. Modelagem matemática em disciplinas do ensino superior: o que manifestam os estudantes? Educere et Educare, Cascavel, v. 12, n. 24, p. 1-15, 2017.

ZOMPERO, A. F.; GONÇALVES, C. E. S.; LABURÚ, C. E. Atividades de investigação na disciplina de ciências e desenvolvimento de habilidades cognitivas relacionadas a funções executivas. Ciência \& Educação, Bauru, vol. 23, n. 2, p. 419-436, 2017. Disponível em: <http://dx.doi.org/10.1590/1516-731320170020009>. Acesso em: 17 maio 2018.

ZÔMPERO, A. F.; LABURÚ, C. E. Atividades investigativas no ensino de ciências: aspectos históricos e diferentes abordagens. Ensaio: pesquisa em educação em ciências, Belo Horizonte, v. 13, n. 3, p. 67-80, 2011. Disponível em: <http://dx.doi.org/10.1590/198321172011130305>. Acesso em: 17 maio 2018.

Artigo recebido em 01/09/2017. Aceito em 22/12/2017.

Contato: Universidade Tecnológica Federal do Paraná, Departamento Acadêmico de Matemática, Avenida dos Pioneiros, 3131, Londrina, PR, 86036-370, Brasil. 